\title{
Activity patterns of residents in homes for the elderly in Alexandria, Egypt
}

\author{
F.A. Hallaj, ${ }^{1}$ M.M. El Geneidy, ${ }^{2}$ H.H. Mitwally ${ }^{3}$ and H.S. Ibrahim ${ }^{2}$
}

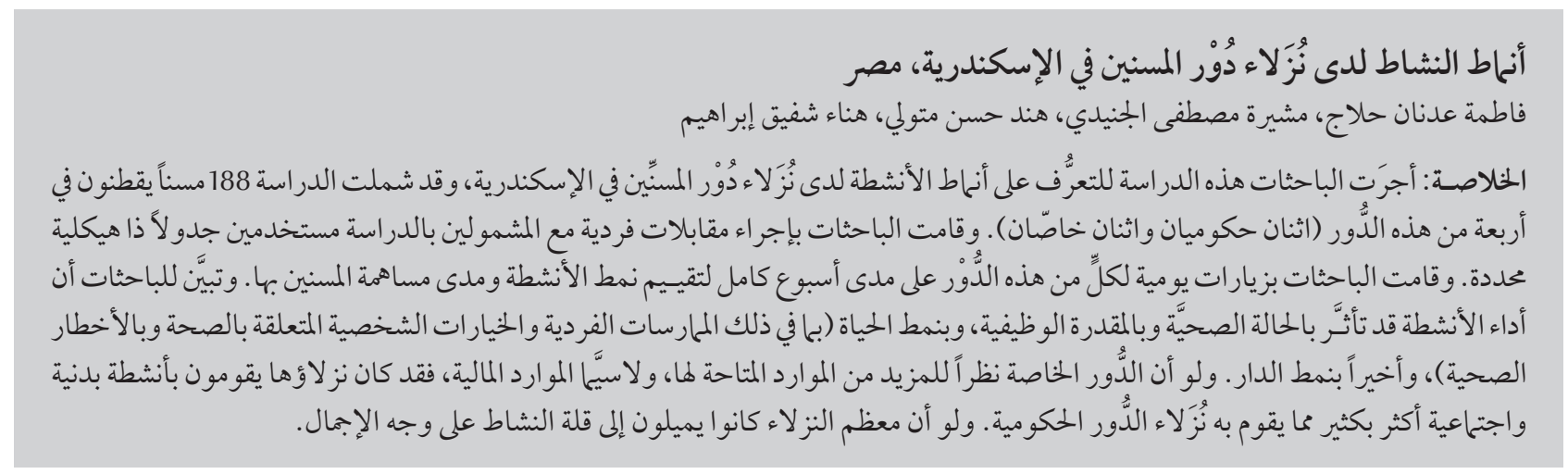

ABSTRACT To identify activity patterns of residents in homes for the elderly in Alexandria, we carried out a study on 188 elderly persons in 4 homes ( 2 governmental and 2 private). Participants were interviewed individually using a structured interview schedule. Each home was visited daily for 1 week in order to assess the type of activities provided and the participation. Performance of activities was affected by health status, functional ability, lifestyle pattern (including individual practices and personal choices related to health and health risk) and type of home. Private homes, having more resources available, particularly financial resources, tended to involve their residents in physical and social activities more than governmental ones. The majority of the residents tended to be inactive.

\section{Types d'activités des résidents des maisons pour personnes âgées à Alexandrie, Égypte}

RÉSUMÉ Afin d'identifier le type d'activités des résidents dans les maisons pour personnes âgées à Alexandrie, nous avons mené une étude sur 188 personnes âgées dans quatre maisons (deux publiques et deux privées). Les participants ont été interrogés individuellement lors d'un entretien structuré. Chaque maison a été visitée quotidiennement pendant une semaine afin d'évaluer le type d'activités proposées et la participation. La participation aux activités dépendait de l'état de santé, des capacités fonctionnelles, du mode de vie (y compris des pratiques individuelles et des choix personnels liés à la santé et au risque sanitaire) et du type de maison. Les maisons privées, disposant de plus de ressources, notamment financières, avaient plus tendance que les maisons publiques à faire participer leurs résidents à des activités physiques et sociales. La majorité des résidents avaient tendance à être inactifs. 


\section{Introduction}

Pursuing a physically active lifestyle arrests or significantly delays age-related changes associated with cardiovascular, respiratory, and musculoskeletal functions and delaysmany of the physical and psychological problems that commonly occur with aging. Regular physical activity helps, maintains, and enhances functional ability, health and psychological well-being of elderly people [1-3]. Social networks and relationships not only provide essential psychological support, but are also a source of instrumental aid, which is needed in times of crisis and illness. They also provide the elderly with a sense of belonging, security, identity, and self worth, enabling them to enjoy life more fully $[4,5]$.

Mobility is considered a prerequisite for independence. Studies in Alexandria have reported that the majority of residents in elderly homes were independent in performing activities of daily living [6-8]. Another study conducted in homes for the elderly in Alexandria revealed that only a small proportion of residents practised walking [9].

Social activities include participation in volunteer work or social clubs, social groups, watching television, reading, listening to radio, using telephone, visits to and from family and friends, attendance of religious activities, entertainment, and participation in activities such as trips, sports, playing games or cards, walking and joining exercise programmes [10]. Studies in Alexandria showed that most elderly persons usually engage in passive activities such as watching television that may affect their functional ability and accelerate dependency $[6,8,11]$.

Many physical and psychosocial factors affect the ability of elderly people to perform activity. The physical factors include age-related changes, particularly decrease in muscle mass, muscle strength and bone mass; response to activity; and poor vision or hearing [12].
The presence of chronic diseases and their complications also affects ability to perform activities [1]. Among the psychosocial factors are depression, isolation, and loss, which affect the desire and motivation to carry out activities [13]: loss of home or relocation has a significant role [14]. The institutional routine may hinder the ability of the elderly person to perform activities of daily living independently. Caregivers believe that they are assisting their clients by allowing them to be sedentary; this may lead to further dependency [15].

Physically, inactivity can lead to poor appetite, which affects food intake leading to poor nutritional status and further weakness. In addition this affects bone mass, joint stiffness and muscle atrophy, which increase the liability to fall and the occurrence of fractures. Psychosocial consequences of inactivity include feelings of boredom and frustration, and a decrease in the ability to interact with others. This may lead to depression, social isolation and increasing dependency. This in turn may lead to caregiver stress, elderly abuse and accelerated death. Most of these problems can be avoided or resolved through participation in various activities $[4,12,16]$.

The aims of this study were to identify the physical and social activities performed by residents in elderly homes and determine factors affecting activity performance among residents in homes for the elderly in Alexandria, Egypt.

\section{Methods}

The study was carried out in 4 homes for the elderly in Alexandria (2 governmental selected by ballot from the available 6 out of the 7 private homes, 2 were included in the study because Arabic is their mother tongue). All residents aged $\geq 60$ years were eligible to participate in the study. The total number of residents was 249 . Those fulfilling the study criteria were 206; 18 refused to participate in the study, leaving 188 participants, 85 from governmental homes and 103 from private ones.

A few residents were suspicious about the interview and refused to talk. In these cases, the researcher resorted to their friends either to persuade them or to attend the interview to make them feel secure and cooperate.

Official approval to carry out the study was obtained from the Ministry of Social Solidarity in Alexandria. The study tools were validated by 10 experts in the field of the study and reliability of the tools was tested by using test-retest reliability. Spearman's correlation coefficient $(r)$ was 0.971.

Informed consent was obtained from the participants after explaining the purpose of the study. After that, each resident who fulfilled the study criteria (aged $\geq 60$ years, able to communicate, accepted to participate, available at the time of the study) was interviewed individually by the researchers using a structured interview schedule to identify his activity pattern and associated factors. In addition, his medical history from the medical records was reviewed. The time of the interview ranged from 30 minutes to 1 hour, depending on the level of understanding and cooperation of the participant.

The ability of the participants to perform activities of daily living (ADLs) was assessed using the Barthel Scale [17]. This assesses feeding, bathing, grooming, dressing, bowels, bladder, toilet, bed/ chair transfer, ambulation, and stairs.

Each home for the elderly was visited daily for 1 week in order to assess and determine the type of daily activities provided by the institution for their residents using an observation checklist, which included 29 items related to the type of activities provided, including physical and social activities.

Data collection started from the 1 April to the end of July 2006 (4 months). 


\section{Statistical analysis}

Data were analysed using SPSS, version 13.0. We used: chi squared to test the association between 2 qualitative variables or to detect differences between 2 or more proportions; Fisher exact test (FET) and Monte Carlo probability (MCP) were used when chi squared was not valid ( $>20 \%$ of the expected cells had count $<5$ ). I-value $<0.5$ was considered significant.

\section{Results}

The age of the participants ranged from 60 to 90 years, with a mean of 72.19 [standard deviation (SD) 5.78] years. There were more females (71.3\%) than males. Illiteracy was observed in almost one-quarter $23.9 \%$ of the sample. About three-quarters of the participants were widows and $45.2 \%$ had not worked outside the home (i.e. housewives) before their admission to the home for the elderly. The mean monthly income for those in private homes was 1082.32 (SD 708.79) Egyptian pounds (LE), while for those in the government homes it was 282.89 (SD 259.77) LE. Just over $85 \%$ had chronic diseases; the most commonly encountered types were cardiovascular 54.8\%, musculoskeletal $43.6 \%$, metabolic $31.9 \%$, and neurological $12.8 \%$. More than half the $(52.7 \%)$ needed assistance in performing daily activities. The duration of stay in the home ranged from 1 month to 15 years with a mean of 3.65 (SD 3.89) years

Walking was the most frequently practised physical activity (38.8\% of the respondents reported walking regularly and $26.1 \%$ sometimes) (Table 1). Few residents (3.2\%) practised sports regularly, but one-fifth practised isometric exercises. Physiotherapy was attended regularly by $10.0 \%$ of respondents.

Social visits from friends and family inside the home was reported by $65.4 \%$ of the participants as regular. Entertainment with other elderly residents was claimed by $89.9 \%$ to be a regular practice (Table 1).

Regular participation in trips outside the home was reported by only $31.9 \%$ of the respondents and visits to friends or family were reported as regular by $25.8 \%$. Hobbies such as reading, fishing and/or gardening were reported by $30.9 \%$ as regular. Those who participated in volunteer work such as helping others, helping in the kitchen, making the menu for the home, participating in teaching or meetings, or helping in organization of trips, members in charity organization were reported by 5.9\% to be regular (Table 1).

The main reported causes for not performing physical activities were lack of motivation, absence of resources, and health status $(48.6 \%, 21.3 \%$, and $16.9 \%$ respectively) (Table 2 ). The main reported causes for not performing social activities were absence of resources and the elders' psychological status (47.4\%, and $20.8 \%$ respectively).

Physical activities were affected significantly by some characteristics of the residents and the type of home but not by age or education (Table 3 ).

Social activities were affected significantly by some characteristics of the residents and the type of home but not by age (Table 3 ).

\section{Discussion}

Our findings indicate that for the physical activity, walking is the one most frequently practised by elders. This may be related to the elders' life style pattern during early life, walking regularly may have been the norm during adulthood. This supports the findings of other studies $[7,18]$. Practising sports was reported by only a small proportion of the sample. This may due to unavailability of the necessary material resources in most of the studied homes. The same was observed in another study conducted in Alexandria where only a quarter of residents practised $\geq 1$ types of sports [7].

In relation to other physical activities performed by the residents. The different types of isometric exercises such as respiratory and abdominal muscle exercises were practised either regularly or sometimes by less than half of the elders. This may be due to their lack of knowledge or lack of motivation. This supports the findings of other studies $[18,19]$. Physiotherapy sessions were attended regularly by less than a quarter of the participants. This may be because the physiotherapy sessions are charged and may be beyond the financial capability of the residents; in addition, this service was not available in the governmental homes.

Stimulating social interaction for the elderly is a vital aspect for a positive quality of life. The study showed that the social interaction inside the home was reported by the majority of residents. However, most of these visits, with the exception of those of home peers, were mainly for paying the fees for the home. These results support those reported by Sorour [9] but contradict those of Mohamed who reported lower percentages [20]. On the other hand, social activities outside the home such as participation in trips were reported by half of the residents. More than twothirds participated in trips in another study done in homes for the elderly in Alexandria [9]. This discrepancy may be rationalized as participation in trips is restricted to only healthy independent residents, while dependent or partially dependent residents needed special attention, which cannot be provided by governmental homes.

Entertainment with other elders in the home is another type of social activity which was reported by the majority of participants. This may be because those in governmental homes live in shared rooms, and this probably increased the chance of social interaction. The same was reported in anther study conducted 


\begin{tabular}{|c|c|c|c|c|c|c|c|c|}
\hline \multirow[t]{2}{*}{ Activity } & \multicolumn{2}{|c|}{ Regularly } & \multicolumn{2}{|c|}{ Sometimes } & \multicolumn{2}{|c|}{ Never } & \multicolumn{2}{|c|}{ Total } \\
\hline & No. & $\%$ & No. & $\%$ & No. & $\%$ & No. & $\%$ \\
\hline \multicolumn{9}{|l|}{ Physical } \\
\hline \multicolumn{9}{|l|}{ Isotonic } \\
\hline Walking & 73 & 38.8 & 49 & 26.1 & 66 & 35.1 & 188 & 100.0 \\
\hline Sports & 6 & 3.2 & 14 & 7.4 & 168 & 89.4 & 188 & 100.0 \\
\hline Isometric & 38 & 20.2 & 44 & 23.4 & 106 & 56.4 & 188 & 100.0 \\
\hline Physiotherapy & 19 & 10.1 & - & - & 169 & 89.9 & 188 & 100.0 \\
\hline \multicolumn{9}{|l|}{ Social } \\
\hline \multicolumn{9}{|l|}{ Inside the home } \\
\hline Visits from friends or familya & 119 & 65.4 & 50 & 27.5 & 13 & 7.1 & 182 & 100.0 \\
\hline Entertain with other residents ${ }^{b}$ & 134 & 89.9 & 15 & 10.1 & - & - & 149 & 100.0 \\
\hline Participate in parties & 93 & 49.5 & 51 & 27.1 & 44 & 23.4 & 188 & 100.0 \\
\hline Practice hobbies & 58 & 30.9 & 36 & 19.1 & 94 & 50.0 & 188 & 100.0 \\
\hline Receive phone calls $s^{\mathrm{a}, \mathrm{c}}$ & 134 & 73.6 & - & - & 48 & 26.4 & 182 & 100.0 \\
\hline Attend religious meetings & 38 & 20.2 & 37 & 19.7 & 113 & 60.1 & 188 & 100.0 \\
\hline Watch TV with others & 13 & 6.9 & 49 & 26.1 & 126 & 67.0 & 188 & 100.0 \\
\hline Eat in the dining room & 41 & 21.8 & - & - & 147 & 78.2 & 188 & 100.0 \\
\hline Play games with others & 12 & 6.4 & 13 & 6.9 & 163 & 86.7 & 188 & 100.0 \\
\hline \multicolumn{9}{|l|}{ Outside the home } \\
\hline Participate in trips & 60 & 31.9 & 38 & 20.2 & 90 & 47.9 & 188 & 100.0 \\
\hline Visit their friends or family ${ }^{a}$ & 47 & 25.8 & 45 & 24.7 & 90 & 49.5 & 182 & 100.0 \\
\hline Go to mosque/church & 26 & 13.8 & 29 & 15.4 & 133 & 70.7 & 188 & 100.0 \\
\hline Go to a club & 3 & 1.6 & 38 & 20.2 & 147 & 78.2 & 188 & 100.0 \\
\hline Participate in volunteer work & 11 & 5.9 & 21 & 11.2 & 156 & 83.0 & 188 & 100.0 \\
\hline
\end{tabular}

${ }^{a} 6$ residents did not have any friends or family members inside or outside the home.

${ }^{b} 39$ residents did not have any friends in the home.

'In governmental homes no telephone is available in the bedrooms but on each floor in some homes and on the ground floor in others, while in the private homes almost all rooms have a phone connection.

in elderly homes in Alexandria by Lachine [11]. Nearly a quarter of reported not receiving any phone calls. This is because in governmental homes no telephone is available in the bedrooms but on each floor in some homes and on the ground floor in others, while in the private homes almost all rooms have a phone connection. Playing games with others was reported by less than a fifth. In an American study more than one-third of the residents played games [21]. Approximately one-quarter visited friends or family. This was in agreement with Sorour [9]. Mohamed reported that only one-third of the residents used to visit family or friends outside the home [20]. This contradiction may be interpreted as in present study approximately one third of the participants were independent in performing ADLs and were able to go outside and visit their families and friends. Less than onefifth went to a club outside the home. This may be explained by the limited income of residents and transportation difficulties.

Attending religious meeting and watching television were practised by nearly one-third of the participants. This is supported by another study carried out in Alexandria where only one-third reported watching television

\begin{tabular}{|c|c|c|c|c|c|}
\hline \multirow[t]{2}{*}{ Activity } & \multicolumn{5}{|c|}{ Reason (\%) } \\
\hline & Health status & Negativism & Psychological status & Lack of motivation & Lack of resources \\
\hline Physical & 16.9 & 7.6 & 2.6 & 48.6 & 21.3 \\
\hline Social & 12.4 & 2.0 & 20.8 & 15.8 & 47.4 \\
\hline
\end{tabular}




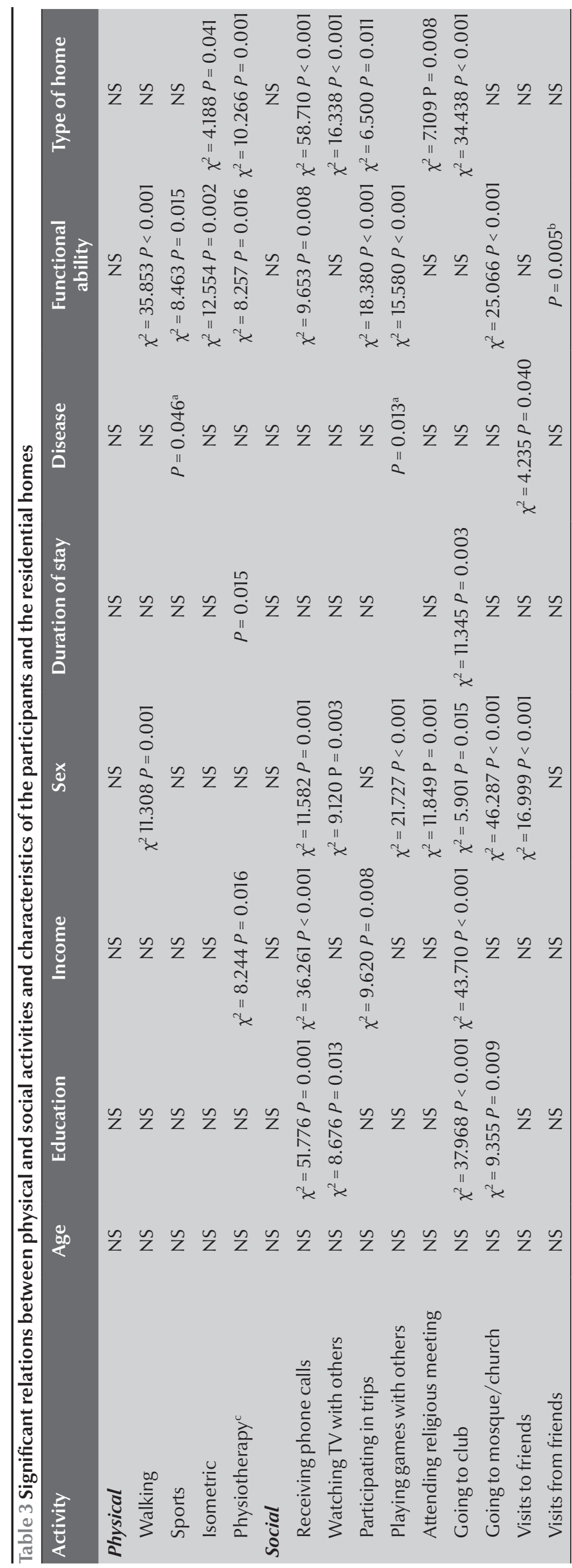

[7]. Hobbies such as reading, or fishing, and/or gardening were performed regularly by half the sample. Sorour indicted that about one-quarter of participants performed hobbies [9]. This may be due to the lack of: resources, facilities or motivation.

The main reasons for not participating in physical and social activities were health status, psychological status, lack of resources and lack of motivation. The same reasons were reported in studies carried out in the United States of America, which emphasized that the causes of non-participation were related to physical limitations [22], selfconsciousness, lack of company, lack of enjoyment and lack of knowledge [18]. A study done in homes for the elderly in Alexandria reported that the most common causes for not participating in social activities were physical disability, transportation difficulties, lack of interest or preference to be alone [22]. Pain has also been reported to be a main factor affecting participation in social activities [9].

Income, sex, functional ability and health status were among the factors that significantly affected activity performance. Duration of stay in the home and the type of home had a positive effect on activity performance. This may be because those in private homes had a good life style pattern throughout their lives and better education and a higher income, sufficient to meet and satisfy their needs, both physical and social. These factors can help them to maintain the activities they used to perform earlier in life. Residents in governmental homes had low education, and low income. This is why only their basic needs are met by the home, and their hobbies are not supported except through donations.

\section{Limitations of the study}

Some difficulties were encountered by the researcher during the process of data collection. Some were resolved such as entering elderly homes, but this 
affected the study in that it required more time with the residents to collect the data as the researcher took an appointment from the resident either in the morning, noon or afternoon. In addition, sometimes the researcher had to visit some residents several times on a social basis to establish a trusting relationship and gain the cooperation of the elderly person before collecting the necessary data. It sometimes necessitated the researcher staying in the home for almost 12 hours/ day (09:00-21:00) to complete the work.

\section{References}

1. Ebersole P, Hess P. Geriatric nursing \& healthy aging. St Louis, Mosby, 2001:120-3, 217-231.

2. Evans G et al. Oxford textbook of geriatric medicine, 2nd ed. New York, Oxford University Press, 2000:1139-1143.

3. Wade L, Waters K. A textbook of gerontological nursing. London, Bailliere Tindall, 1996:314-316.

4. Kane R, Ouslander J, Abrass I. Essentials of clinical geriatrics, 4th ed. New York, McGraw-Hill, 1999:256-262.

5. Zurakowski T. The social environment of nursing homes and the health of older residents. Holistic Nursing Practice, 2003, 14(4):12-23.

6. ElGameel M. Study of falls among institutionalized elderly in Alexandria [MSc thesis]. Alexandria, University of Alexandria, Faculty of Nursing, 2001.

7. Fouad R. Nutritional assessment of elders and development of nutritional educational program to caregivers [DNSc thesis]. Alexandria, University of Alexandria, Faculty of Nursing, 2004.

8. Shafik H. Impact of reminiscence therapy on self esteem among residents of elderly homes [DNSc thesis]. Alexandria, University of Alexandria, Faculty of Nursing, 2004.

9. Sorour D. Pain coping strategies among residents of elderly homes [MSc thesis]. Alexandria, University of Alexandria, Faculty of Nursing, 2005.

10. Kane R. Assessing older persons. New York, Oxford University Press, 2000, 170-97; 725-728.

11. Lachine $\mathrm{O}$. The effect of a nursing intervention program on the loneliness experienced by elderly people [DNSc thesis]. Alexandria, University of Alexandria, Faculty of Nursing, 1998.
12. Staab A, Hodges L. Essentials of gerontological nursing adaptation to the aging process. Philadelphia, JB Lippincott, 1996:51-56.

13. Lueckenotte A. Gerontologic nursing. 2nd ed. St Louis, Mosby, 2000:212-5, 343-345.

14. Mass M et al. Nursing care of older adults. St. Louis, Mosby, 2001:615-626.

15. Eliopoulos C. Gerontological nursing, 3rd ed. Philadelphia, JB Lippincott, 1993:93-107; 106-110; 141.

16. Wold G. Basic geriatric nursing, 3rd ed. St Louis, Mosby, 2004:255-275.

17. Barthel Scale (1965). In Burke M, Laramie J. Primary care of the older adult, 2nd ed. St Louis, Mosby, 2004:23;31-61.

18. Dergance J, Calmbach W. Barriers to and benefits of leisure time physical activity in the elderly: differences among cultures. Journal of the American Geriatrics Society, 2003, 51(6):863-886.

19. Struck B, Ross K. Health promotion in older adults: prescribing exercise for the frail and home bound. Geriatrics, 2006, 61(5):22-27.

20. Mohamed A. Effect of institutionalization on the cognitive ability of the elders [MSc thesis]. Alexandria, University of Alexandria, Faculty of Nursing, 2005.

21. Verghese $\mathrm{J}$ et al. Leisure activities and the risk of dementia in the elderly. New England Journal of Medicine, 2003, 348(25):2508-2516.

22. Bertera E. Physical dysfunction and social participation among racial/ethnic groups of older Americans. Journal of Religion in the Social Services, 2001, 20(4):12-18. 